\title{
Autoshaping the pigeon's keypeck in a dark chamber
}

\author{
FERNANDO OBERDIECK, DEBORAH L. MUELLER, and CARL D. CHENEY \\ Utah State University, Logan, Utah 84322
}

\begin{abstract}
Pigeons were exposed to an autoshaping procedure in a dark chamber with a punctate conditioned stimulus signaling response-independent food presentations. Contrary to other findings, a high rate of autoshaped keypecking emerged and was sustained in all subjects. Although these results support a cue localization hypothesis, they also implicate the importance of the context in which a conditioned stimulus is presented in the autoshaping paradigm.
\end{abstract}

Brown and Jenkins (1968) found that if a response key is briefly transilluminated prior to responseindependent grain presentations, experimentally naive pigeons will soon begin pecking the key when it is lit. This behavioral phenomenon, termed "autoshaping" by Brown and Jenkins, has been exhaustively reviewed by both Hearst and Jenkins (1974) and Schwartz and Gamzu (in press). Although autoshaped keypecking reliably emerges under a variety of conditions, it reportedly will not occur if the key-light/grain pairings take place in a chamber that is completely dark between trials (Wasserman, 1973).

Wasserman accounted for the necessity of the houselight on the emergence of autoshaped keypecking in terms of informativeness and cue redundancy. He reasoned that with the houselight off, key illumination could be detected from anywhere in the chamber because illumination of the key inevitably brightened the entire chamber. Since brightening of the chamber resulted in a variety of redundant contextual cues (reflections), the pigeons did not have to attend to the relatively small response key. On the other hand, with the houselight on, food presentation could be predicted only if the pigeon oriented toward the key or an area near it.

Although Wasserman's explanation emphasizes the importance of cue localizability in autoshaping, it does not necessarily preclude the occurrence of autoshaping in a dark chamber. If the cue localizability hypothesis is correct, use of a punctate conditioned stimulus (CS) in a dark chamber could result in the emergence of autoshaped keypecking. Since a punctate CS would not illuminate the dark chamber, it would fail to provide the pigeon with redundant contextual cues. As a consequence, imminent food delivery could be predicted only if the pigeon oriented to the subtle punctate CS.

This reasoning suggested that a punctate CS in a dark chamber is functionally equivalent to a larger CS (i.e., fully illuminated response key) in an illuminated chamber. That is, autoshaped keypecking should emerge in the former case since it has been repeatedly demonstrated in the latter. The following study was undertaken to examine this possibility.

\section{METHOD}

\section{Subjects}

Three experimentally naive wild homing pigeons were trapped and allowed to free feed for 10 days prior to the experiment. Throughout the experiment, they were maintained at approximately $80 \%$ of their free-feeding weight, with water available in their individual home cages at all times.

\section{Apparatus}

Subjects were tested in a three-key operant conditioning chamber with the following internal dimensions: $40.64 \times 40.64$ $x 40.64 \mathrm{~cm}$. Three of the walls were made of unburnished aluminum and the fourth of clear Plexiglas. This chamber was positioned inside a larger sound-attenuating chamber that also contributed to restricting ambient light. Both chambers were located inside a nonlighted room. The $2.22-\mathrm{cm}$ diam response keys were located in line with their centers $22.86 \mathrm{~cm}$ above the wooden floor. The central key was located on the midline of the intelligence panel, with the centers of the side keys located $6.35 \mathrm{~cm}$ to either side. Side keys were accessible but nonfunctional; only the central key was employed. During CS presentations, the center key was transilluminated by an in-line projector containing a white 28-V dc bulb (Sylvania 28ESB). To operate, the key required a force of approximately $.06 \mathrm{~N}$ and when activated produced an audible feedback click. Reinforcement (4 sec presentation of pigeon chow) was presented through an aperture $(6.35 \times 5.08 \mathrm{~cm})$ centrally located on the front wall with its top $10.16 \mathrm{~cm}$ below the center of the central key. During reinforcement, the aperture was illuminated by a white $28-\mathrm{V}$ light bulb (G. E. 757). No general illumination was provided to the chamber at any time. White noise masked extraneous sounds. Electromechanical components situated in an adjoining room recorded data and controlled experimental events.

To produce a punctate CS, the front of the in-line projector was covered with black construction paper containing a small perforation. The result was that, during transillumination, the response key was dark except for a centrally located $.15-\mathrm{cm}$ diam circular area of white light measuring $4 \mathrm{fc}$ (43.04 lux) at $3 \mathrm{~cm}$ with a Sekonic L28c2 exposure meter.

\section{Procedure}

On Day 1 , subjects were magazine trained in the chamber with the houselight on and all keys darkened. They were individually placed in the chamber with the magazine tray in the elevated position. After the subject had eaten for $10 \mathrm{sec}$, the food tray was lowered and immediately raised again to allow the pigeon to eat for another $10 \mathrm{sec}$. On the following three trials, the food tray was elevated for $3 \mathrm{sec}$ at 15 -sec intervals. Subsequently, the food tray was operated for five trials each at 30 -, 45-, and 60-sec intervals (in that order), remaining in the elevated position for $3 \mathrm{sec}$. Failure to eat from the food hopper on 
three consecutive trials resulted in the food tray remaining in the elevated position until the subject had eaten for $3 \mathrm{sec}$.

Autoshaping sessions began on Day 2 and continued for 20 consecutive days. Sessions consisted of 40 trials, with each 8-sec CS presentation followed by a 4-sec response-independent grain presentation. The CS presentations were separated by variabletime intertrial intervals (ITIs) averaging $60 \mathrm{sec}$ (range: 5-216 sec). Keypecks were recorded but had no scheduled consequences. Responses during the ITI were recorded cumulatively throughout the session, whereas pecks during CS presentations were recorded on a trial-by-trial basis.

\section{RESULTS AND DISCUSSION}

Acquisition of keypecking was defined as occurring on the first trial of a consecutive sequence of five trials containing at least one peck (Newlin \& LoLordo, 1976). Subjects B, Y, and DB acquired in the first session on Trials 33,10 , and 13 , respectively. The first peck occurred on Trials 6,10 , and 3 for B, Y, and DB, respectively.

Figure 1 depicts the number of key illuminations during which at least one response occurs as a function of successive training days. Responding occurred during nearly all key illuminations for all subjects, indicating quite clearly that autoshaped keypecking will emerge in a dark chamber if a punctate CS is employed. The average rate of responding (across all sessions) during CS illumination varied considerably, being 2.14 , .31 , and 1.50 responses/sec for Subjects B, Y, and DB, respectively. Some ITI responding also occurred but
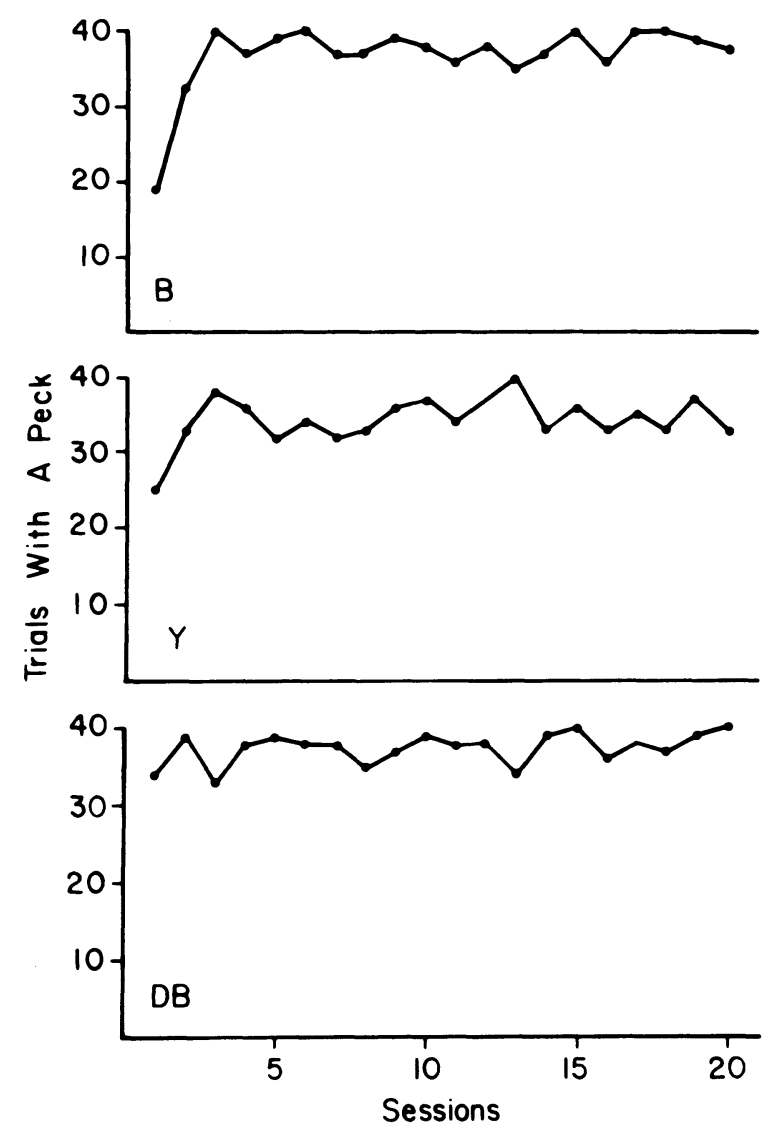

Figure 1. The number of trials containing at least one response during successive sessions. was infrequent; the ratios of ITI responses to CS responses, averaged across all sessions, were .02 (B), .06 (Y), and .03 (DB). Nearly all ITI responses were runover pecks, that is, the subject began pecking during CS illumination and continued responding after light offset.

The emergence of autoshaped keypecking in pigeons is clearly not dependent on general chamber illumination, as both Hearst and Jenkins (1974) and Wasserman (1973) suggested. The critical factor appears to be not the general chamber illumination but the relative localizability of the CS. Consequently, the present experiment does not contradict, but rather supports, the cue localization hypothesis proposed by Wasserman. It should be noted, also, that Wasserman did obtain some autoshaped keypecking (Experiments 2 and 3) without a houselight on. But even under his optimal conditions, pecks occurred on the average on only $39 \%$ of the trials, far less than in the present experiment. Hitzing and Safar (1970) is the only other report of autoshaped keypecking in a dark chamber but, as Wasserman noted, their unconventional preexperimental procedures make any conclusions uncertain.

Perhaps the major conclusion to be drawn is that stimulus characteristics are not absolute but interact with the context in which they are presented. If Wasserman's data is viewed as a control group (Experiment 1), it is obvious that a punctate CS will engender autoshaped keypecking in a dark chamber, whereas a fully illuminated response key will not. This leads one to suspect that both stimulus characteristics and their context are important variables in response-independent procedures. The recent work examining biological constraints on learning (e.g., Seligman \& Hagar, 1972) could be used to further support such a view, since signal characteristics have been found to be of major importance and should therefore merit more experimental attention.

\section{REFERENCES}

Brown, P. L., \& Jenkins, H. M. Auto-shaping of the pigeon's key peck. Journal of the Experimental Analysis of Behavior, 1968, 11, 1-8.

HeARST, E., \& Jenkins, H. M. Sign-tracking: The stimulusreinforcer relation and directed action. Austin, Texas: Psychonomic Society, 1974.

Hrtzing, E. W., \& Safar, T. Auto-shaping: The conditions necessary for its development and maintenance. Psychological Record, 1970, 20, 347-351.

Newlin, R. J., \& LoLordo, V. A comparison of pecking generated by serial, delay, and trace autoshaping procedures. Journal of the Experimental Analysis of Behavior, 1976, 25, 227-241.

Schwartz, B., \& GAMzU, E. Pavlovian control of operant behavior: An analysis of autoshaping and its implications for operant conditioning. In W. K. Honig and J. E. R. Staddon (Eds.), Handbook of operant behavior. New York: Prentice Hall, in press.

Seligman, M. E. P., \& Hager, J. L. Biological boundaries of learning. New York: Appleton-Century-Crofts, 1972.

Wasserman, E. A. The effect of redundant contextual stimuli on autoshaping the pigeon's keypeck. Animal Learning \& Behavior, 1973, 1, 198-206.

(Received for publication December 13, 1976.) 